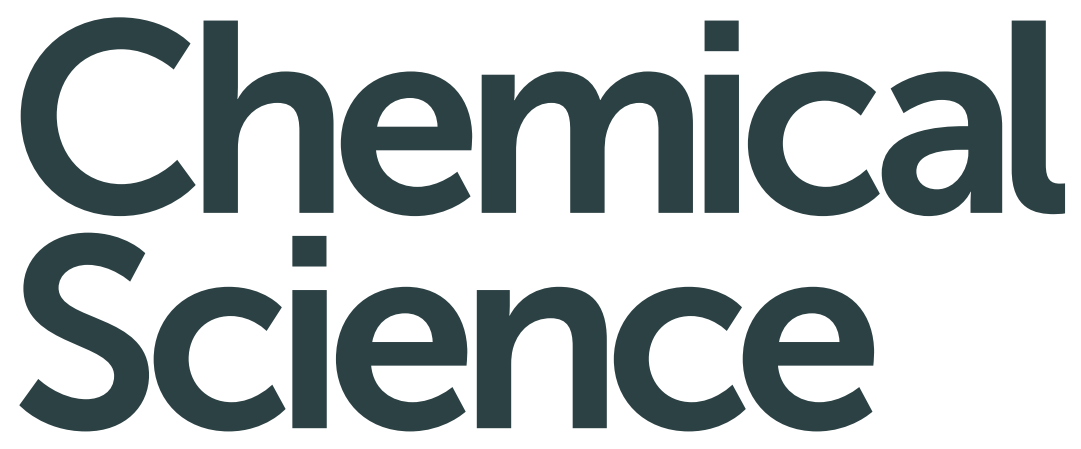

rsc.li/chemical-science

$11 /$

${ }_{4}^{4}$

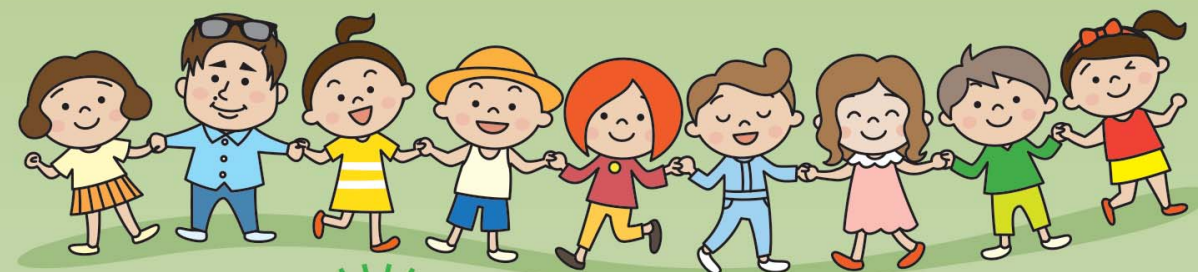

a) 11/1

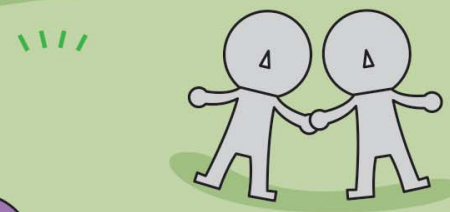

111,3

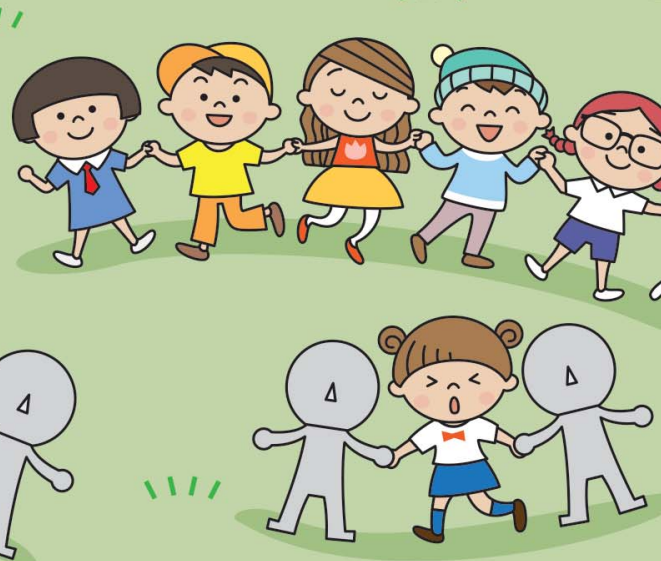

(3) 
Check for updates

Cite this: Chem. Sci., 2019, 10, 6770

๑ All publication charges for this article have been paid for by the Royal Society of Chemistry

Received 2nd May 2019

Accepted 21st June 2019

DOI: $10.1039 / \mathrm{c} 9 \mathrm{sc0} 02151 \mathrm{e}$

rsc.li/chemical-science

\title{
Living supramolecular polymerization based on reversible deactivation of a monomer by using a 'dummy' monomer
}

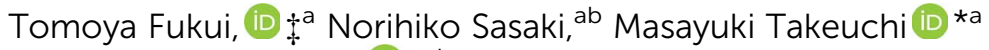 \\ and Kazunori Sugiyasu (D) *ab
}

\begin{abstract}
Although living supramolecular polymerization (LSP) has recently been realized, the scope of the monomer structures applicable to the existing methods is still limited. For instance, a monomer that spontaneously nucleates itself cannot be processed in a manner consistent with LSP. Herein, we report a new method for such a "reactive" monomer. We use a 'dummy' monomer which has a similar structure to the reactive monomer but is incapable of one-dimensional supramolecular polymerization. We show that in the presence of the dummy monomer, the reactive monomer is kinetically trapped in the dormant state. In this way, spontaneous nucleation of the reactive monomer is retarded; yet, addition of seeds of a supramolecular polymer can initiate the supramolecular polymerization in a chain growth manner. As a result, we obtain the supramolecular polymer of the reactive monomer with a controlled length, which is otherwise thermodynamically inaccessible. We believe that this concept will expand the scope of LSP for the synthesis of other functional supramolecular polymers, and thus lead to a variety of applications.
\end{abstract}

\section{Introduction}

Most supramolecular polymerizations occur spontaneously with a negligible activation barrier for initiation. In other words, a monomer is highly "reactive" toward polymerization. Thus, controlling supramolecular polymerization has remained a significant challenge. ${ }^{1}$ On the other hand, a similar issue for covalent bond-based polymerization has been successfully resolved even for radical species, by taming radical polymerization into living radical polymerization (LRP). Though there are several approaches for LRP, almost all the current methods are based on a common principle, in which a reversible and dynamic equilibrium generating a so-called dormant state is coupled with the polymerization reaction (Fig. 1a). ${ }^{2,3}$ The coupled equilibrium decreases the effective concentration of the reactive species (i.e., the propagation sites), thereby allowing for kinetic control of the concurrent polymerization.

${ }^{a}$ Molecular Design \& Function Group, National Institute for Materials Science (NIMS), 1-2-1 Sengen, Tsukuba, Ibaraki 305-0047, Japan.E-mail:TAKEUCHI.Masayuki@nims. go.jp; SUGIYASU.Kazunori@nims.go.jp

${ }^{b}$ Department of Materials Physics and Chemistry, Graduate School of Engineering, Kyushu University, 744 Moto-oka, Nishi-ku, Fukuoka 819-0395, Japan

$\dagger$ Electronic supplementary information (ESI) available. See DOI: 10.1039/c9sc02151e

\$ Present address: Department of Chemistry, University of Victoria, 3800 Finnerty Road, Victoria, B.C. V8P 5C2, Canada.
In the last decade, mechanistic insights into supramolecular polymerization have been significantly enriched, , ${ }^{\mathbf{1 4 - 1 1}}$ and have recently led to the development of living supramolecular polymerization (LSP). ${ }^{\mathbf{1 2 - 3 0}}$ It is intriguing that both LRP and LSP rely on reversible and dynamic equilibrium coupled with the polymerization pathway. So far, the formation of metastable aggregates (Fig. 1b) ${ }^{12-17}$ and intramonomer hydrogen bonds (Fig. 1c), ${ }^{18-23}$ and photoisomerization (Fig. 1d) ${ }^{24}$ have been shown to be effective in generating the dormant states in LSP. In this context, the difference between LRP and LSP is also noteworthy. In LRP, the reactive polymer terminus is deactivated (or "capped") in the dormant state, while in LSP, the spontaneous nucleation of monomers is kinetically suppressed, because of which the monomer itself needs to be deactivated. Inevitably, the monomer design is crucial for achieving LSP, which has limited the scope of the existing methods of LSP for synthesis of other functional supramolecular polymers. In fact, it has been shown that a subtle structural modification in the monomer influences the energy landscape of the self-assembly and often disables the monomer for participating in the LSP. ${ }^{\mathbf{1 3 , 2 0 , 3 1}}$ Herein, we show a new concept that would be more tolerant in terms of the monomer design, in comparison with the other methods reported so far. In the present approach, we use a 'dummy' monomer that is incapable of one-dimensional (1D) supramolecular polymerization but can entrap a "reactive" monomer into the dormant state owing to the structural similarity (Fig. 1e). 
Living radical polymerization (LRP)

(a)

Coupled equilibrium

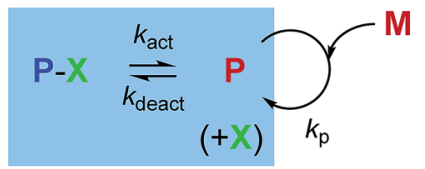

Living supramolecular polymerization (LSP)

(b)

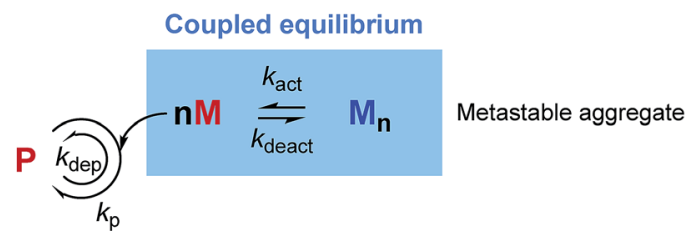

(c)

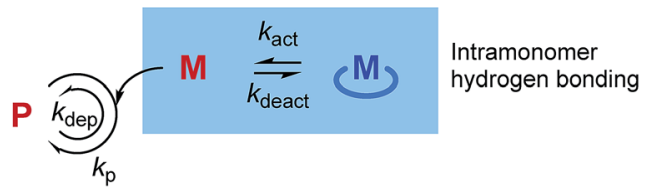

(d)

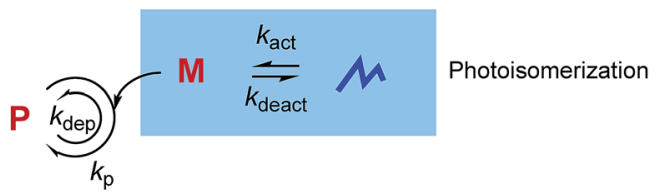

(e)

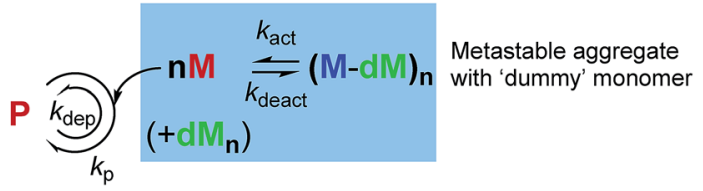

Fig. 1 (a) Mechanism of living radical polymerization (LRP). Existing mechanisms of living supramolecular polymerization (LSP) based on the (b) formation of metastable aggregates, (c) formation of intramonomer hydrogen bonds, and (d) photoisomerization. (e) Proposed mechanism of LSP using a 'dummy' monomer (dM) to entrap the active monomer (M). Species shown in red are reactive, while those shown in blue are dormant.

\section{Results and discussion}

\section{Impact of monomer design on supramolecular polymerization}

The structures of the porphyrin monomers used in this study are shown in Fig. 2. As reported previously, 3Me can be processed in a manner consistent with LSP via the formation of offpathway aggregates as the dormant species (Fig. 1b). ${ }^{12}$ 3Me initially forms a metastable off-pathway aggregate but transforms into a thermodynamically stable supramolecular polymer after a lag time (details are given in Fig. S2 $\dagger$ ). These two aggregates have different porphyrin stacking modes: the former is the J-aggregate while the latter is the $\mathrm{H}$-aggregate. This timedependent transformation allowed for kinetic control of supramolecular polymerization. It should be noted that in practice, a lag time of about an hour is required to perform LSP conveniently.

Despite the structural similarity, the self-assembly of $2 \mathbf{M e}$ was distinct from that of 3 Me. Cooling a hot methylcyclohexane

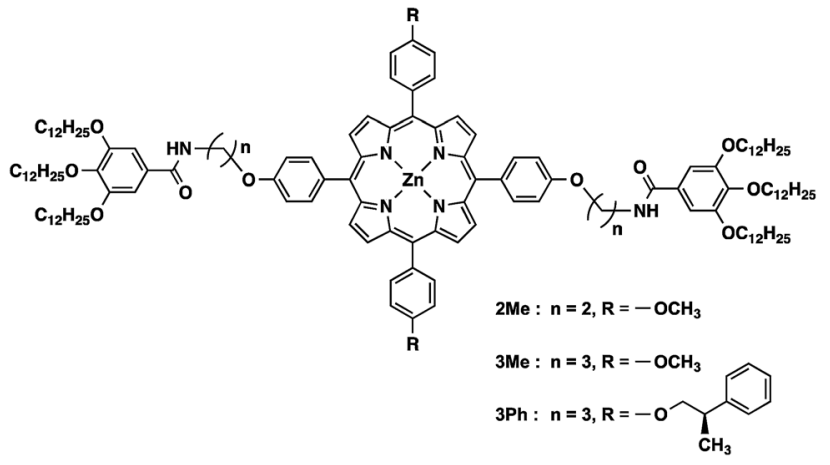

Fig. 2 Structures of porphyrin monomers used in this study. 3Ph is a 'dummy' monomer which has a similar structure to the monomers (2Me and $3 \mathrm{Me}$ ) but is incapable of one-dimensional supramolecular polymerization. ${ }^{31}$

(MCH) solution of 2Me did not form the metastable J-aggregate but immediately resulted in heavily bundled supramolecular polymers as precipitates (Fig. $3 \mathrm{a}-\mathrm{c}$ ). The difference between the self-assembly of $\mathbf{2 M e}$ and $3 \mathbf{M e}$ is attributable to the even-odd effect of the alkylene spacers. ${ }^{32,33}$ We note that Würthner and coworkers $^{20}$ have previously found the length of the alkylene spacers to influence the LSP in a different mechanism (Fig. 1c). These results clearly exemplify the criticality of the monomer design in achieving LSP.

To further gain insights into the supramolecular polymerization of $2 \mathbf{M e}$, we studied the temperature-dependent changes in its absorption spectra (Fig. 3d). Upon cooling $\left(-1.0 \mathrm{~K} \mathrm{~min}^{-1}\right)$, the Soret band underwent a red-shift with the concomitant appearance of isosbestic points ( 373 to $318 \mathrm{~K}$ ), thus suggesting the formation of J-aggregates. ${ }^{12}$ This process was analyzed by the isodesmic model, ${ }^{1}$ which yielded thermodynamic parameters comparable with those of the J-aggregate formation of $3 \mathbf{M e}$ (Fig. S3†). However, further cooling of the solution below $318 \mathrm{~K}$ resulted in the appearance of a blue-shifted Soret band, suggesting the formation of $\mathrm{H}$-aggregates. ${ }^{12,13}$ This process was accompanied by a concomitant increase in the base line due to light scattering by the precipitates, thereby leading to a deviation of the isosbestic points. The complex aggregation behavior as well as the precipitation hindered further mechanistic studies to estimate the thermodynamic parameters.

The turnaround temperature at which the J-aggregates began converting to $\mathrm{H}$-aggregates was dependent on the cooling rate (Fig. 3e). This behavior indicates that the formation of the $\mathrm{H}^{-}$ aggregate of $\mathbf{2 M e}$ is under kinetic control to a certain extent. However, even when a hot solution of $\mathbf{2 M e}$ was quenched in an ice bath, spontaneous nucleation of the H-aggregate could not be prevented. Due to the absence of a lag time, the LSP of 2Me was not feasible (Fig. S4†).

\section{Kinetic trapping of $2 \mathrm{Me}$ by using a dummy monomer, $3 \mathrm{Ph}$}

To address this issue, we conceived a solution based on our previous findings regarding a mixture of $3 \mathbf{M e}$ and $3 \mathbf{P h} .{ }^{31} \mathbf{3 P h}$ has a similar structure to $\mathbf{3 M e}$, and likewise, forms a $\mathrm{J}$ aggregate; however, the steric hindrance of the side chains 
(a)

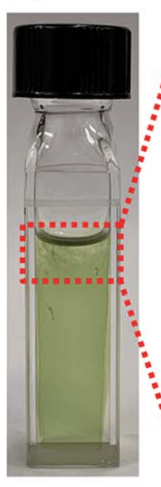

(b)

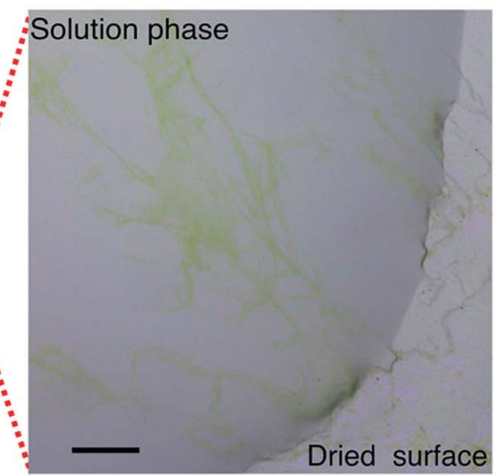

(c)

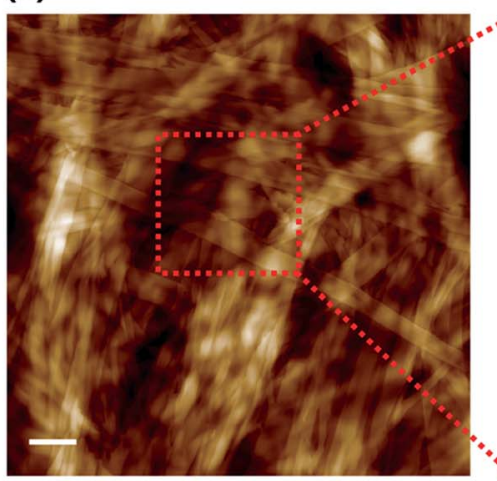

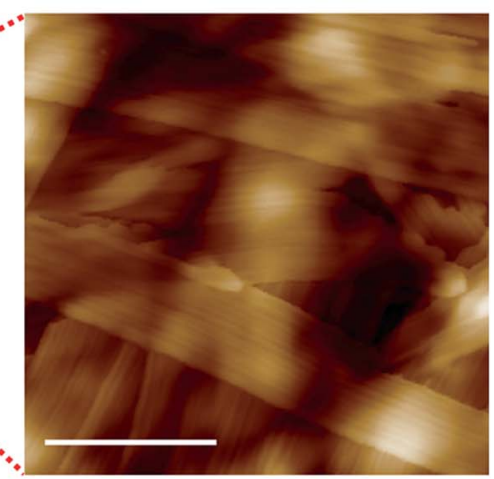

(d)

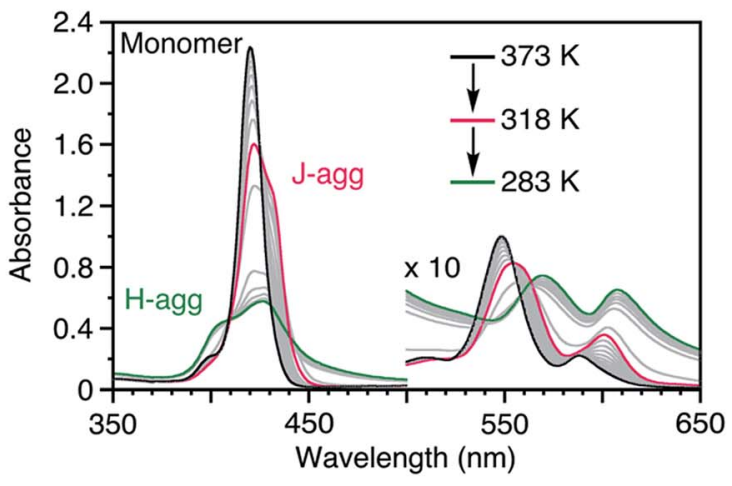

(e)

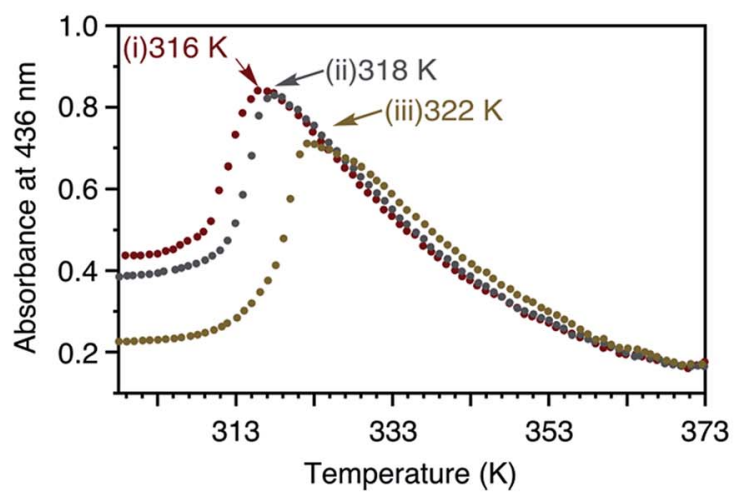

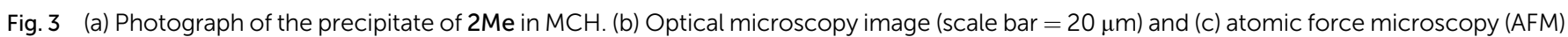

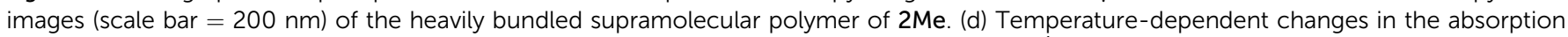

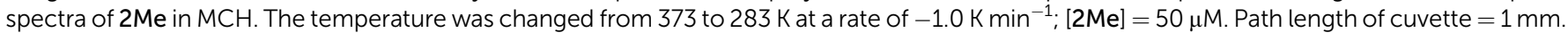

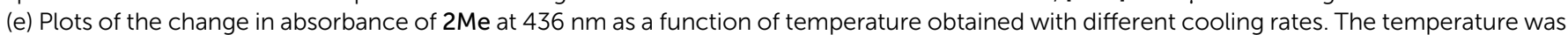
changed from 373 to $283 \mathrm{~K}$ at a rate of (i) $-10 \mathrm{~K} \mathrm{~min}^{-1}$, (ii) $-1 \mathrm{~K} \mathrm{~min}^{-1}$, and (iii) $-0.1 \mathrm{~K} \mathrm{~min}^{-1}$.

prevents the face-to-face stacking of the porphyrin plane (i.e., $\mathrm{H}$ aggregate supramolecular polymerization). When a hot solution of $3 \mathbf{M e}$ and $\mathbf{3 P h}$ in $\mathrm{MCH}$ was cooled down, $3 \mathbf{M e}$ and $3 \mathbf{P h}$ coassembled into a J-aggregate. We found that this coassembled J-aggregate was metastable, and the system showed time-dependent narcissistic self-sorting to the $\mathrm{H}$-aggregates of 3Me and J-aggregates of 3Ph after a lag time. ${ }^{31,34-36}$ Interestingly, this lag time was dependent on the ratio of $\mathbf{3 M e}$ to $\mathbf{3 P h}$; the smaller the ratio, the longer was the lag time. Considering this, we envisaged that if $\mathbf{2 M e}$ and $\mathbf{3 P h}$ could co-assemble to form a Jaggregate owing to the structural similarity, the spontaneous nucleation of the $2 \mathrm{Me} \mathrm{H}$-aggregate would be retarded, thus enabling kinetic control of the supramolecular polymerization of $2 \mathrm{Me}$.

To verify this concept, we studied the temperaturedependent changes in the absorption spectra of $2 \mathbf{M e}$ in the presence of $3 \mathbf{P h}$ (Fig. $4 \mathrm{a}$, molar ratio of $2 \mathbf{M e}: 3 \mathbf{P h}=50: 50$ ). As shown in Fig. 4b, the formation of J-aggregates followed a sigmoidal cooling curve down to room temperature. As such, 2Me was trapped in the J-aggregate in the presence of the 'dummy' monomer, 3Ph (Fig. S5 $\dagger$ ). We infer that the J-aggregate is not crystalline and is tolerant to co-assembly with monomers having different structures. ${ }^{35}$
As in the case of the $\mathbf{3 M e} / \mathbf{3 P h}$ system, ${ }^{31}$ the $\mathrm{J}$-aggregate consisting of $\mathbf{2 M e}$ and $\mathbf{3 P h}$ was also metastable and showed time-dependent spectral changes (Fig. 4c). When we fixed the total concentration of the porphyrins but changed their mixing ratio, the net changes in absorbance with time $\left(\mathrm{Abs}_{t=0}-\mathrm{Abs}_{t}\right)$ were dependent on the proportion of $2 \mathbf{M e}$ (Fig. $4 \mathrm{~d}$ ). This result suggests that $\mathbf{3 P h}$ was not involved in the transformation and remained as a J-aggregate, namely, time-dependent narcissistic self-sorting (Fig. S6†). Furthermore, a larger proportion of $2 \mathbf{M e}$ resulted in a shorter lag time. These results are consistent with those of our previous study. ${ }^{31}$ The resultant lag time (49 min for 2Me $: \mathbf{3 P h}=70: 30)$ was shorter than that of the $3 \mathbf{M e} / \mathbf{3 P h}$ mixture (555 $\mathrm{min}$ for $3 \mathbf{M e}: \mathbf{3 P h}=70: 30)$, because of the higher nucleation propensity of $2 \mathbf{M e}$ as compared with $3 \mathbf{M e}$; nonetheless, it was long enough for the LSP to proceed further.

\section{Living supramolecular polymerization of $2 \mathrm{Me}$}

As an initiator for LSP, we prepared seeds of the supramolecular polymer (i.e., H-aggregate) of $2 \mathbf{M e}$ by sonication, with a number average length $\left(L_{\mathrm{n}}\right)$ of $134 \mathrm{~nm}$ (details are given in the ESI, see Fig. S7 $\dagger$ ). The addition of the seeds to a solution of coassembled $2 \mathbf{M e} / 3 \mathbf{P h}$ J-aggregates (50:50 molar ratio) 
(a)

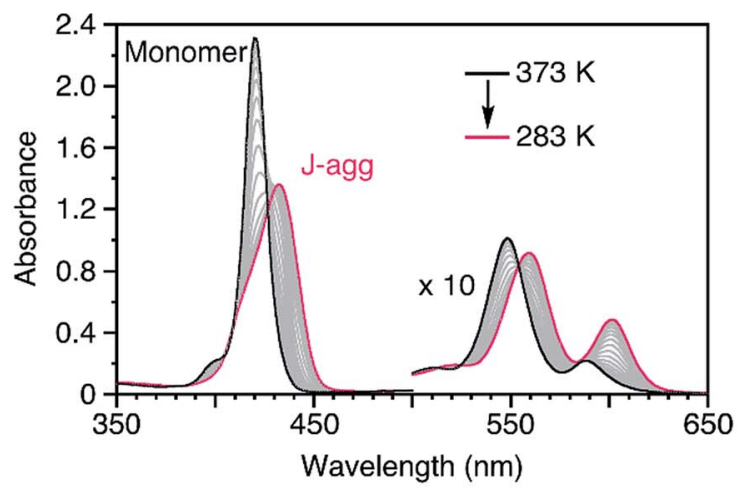

(c)

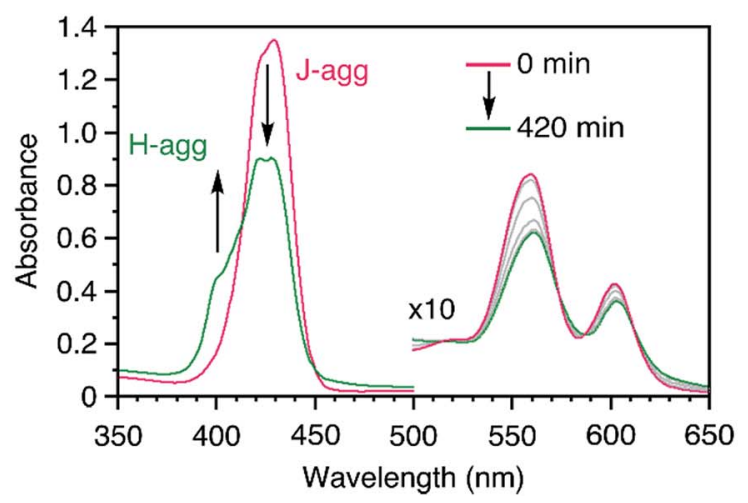

(b)

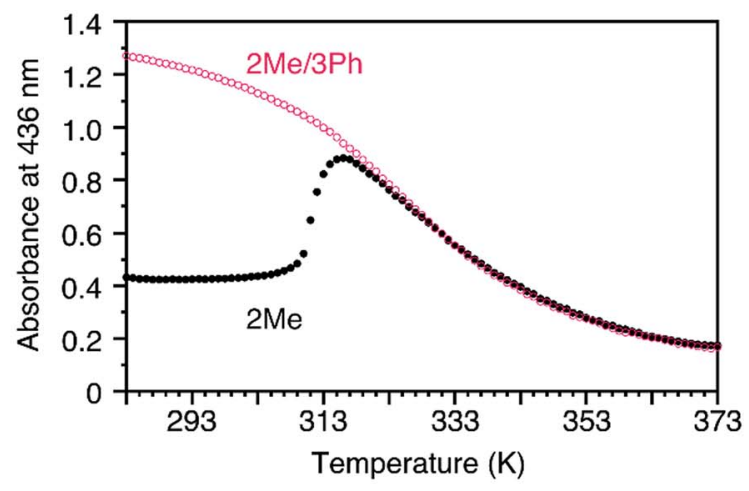

(d)

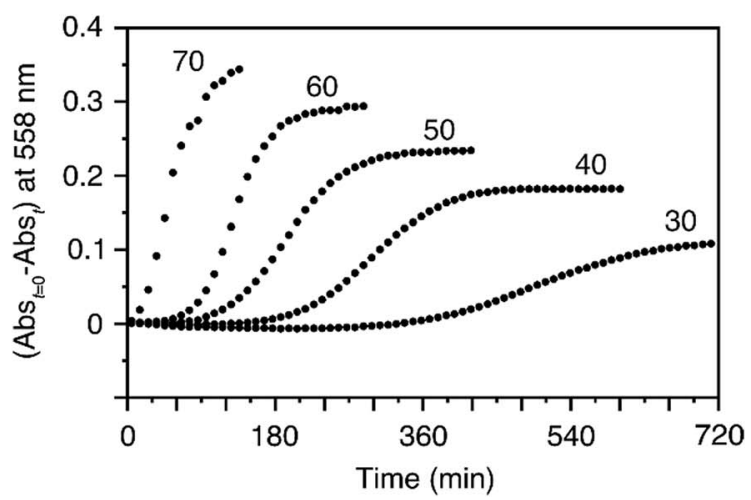

Fig. 4 (a) Temperature-dependent changes in the absorption spectra of $2 \mathrm{Me}$ in the presence of $3 \mathrm{Me}$ in $\mathrm{MCH}$. The temperature was changed from 373 to $283 \mathrm{~K}$ at a rate of $-1.0 \mathrm{~K} \mathrm{~min}^{-1}$; $[2 \mathrm{Me}+3 \mathrm{Ph}]=50 \mu \mathrm{M}, 2 \mathrm{Me}: 3 \mathrm{Ph}$ (molar ratio) $=50: 50$. Path length of cuvette $=1 \mathrm{~mm}$. (b) Plots of the changes in absorbance at $436 \mathrm{~nm}$ as a function of temperature, measured in the presence (pink: a) and absence (black: Fig. 3d) of 3Ph. The temperature was changed from 373 to $283 \mathrm{~K}$ at a rate of $-1.0 \mathrm{~K} \mathrm{~min}^{-1}$; [2Me $+3 \mathrm{Ph}$ ] $=50 \mu \mathrm{M}$. (c) Time-dependent changes in the absorption spectra of a mixture of $2 \mathrm{Me}$ and $3 \mathrm{Ph}$ obtained after cooling a hot solution to $308 \mathrm{~K}$ from $373 \mathrm{~K}$; [ $2 \mathrm{Me}+3 \mathrm{Ph}]=50 \mu \mathrm{M}$, molar ratio of $2 \mathrm{Me}: 3 \mathrm{Ph}=$ 50 : 50 . (d) Plots of the changes in absorbance of a mixture of $2 \mathrm{Me}$ and $3 \mathrm{Ph}$ in $\mathrm{MCH}$ at $558 \mathrm{~nm}$ as a function of time, measured at $308 \mathrm{~K}$; [2Me + $3 \mathrm{Ph}]=50 \mu \mathrm{M}$. The numerical figures indicate the percentage of $2 \mathrm{Me}$ in the co-assembled J-aggregate. Path length of cuvette $=10 \mathrm{~mm}$. The solutions were stirred at a rate of $400 \mathrm{rpm}$.

eliminated the lag time and initiated the supramolecular polymerization (Fig. 5a). The logarithm of the apparent polymerization rate, $\log \left(-\mathrm{d}\left(\mathrm{Abs}_{558}\right) / \mathrm{d} t\right)$, and the amount of the added seed were proportional with a slope of 0.97 , thus indicating a first-order polymerization with respect to the concentration of the seed (Fig. 5b). ${ }^{12}$

With a fixed amount of the seeds, the net changes in absorbance with time $\left(\mathrm{Abs}_{t=0}-\mathrm{Abs}_{t}\right)$ were proportional to the proportion of $2 \mathrm{Me}$ in the co-assembled $2 \mathrm{Me} / 3 \mathbf{P h} \mathrm{J}$-aggregates, which indicated that only $2 \mathrm{Me}$ was involved in the LSP (Fig. $5 \mathrm{c}$ and d). Correspondingly, the polymerization rate $\left(-\mathrm{d}\left(\mathrm{Abs}_{558}\right) / \mathrm{d} t\right)$ was also dependent on the proportion of $\mathbf{2 M e}$ (Fig. 5d, red circle). In this way, the supramolecular polymerization of $\mathbf{2 M e}$, which was otherwise spontaneous, could be kinetically controlled in the presence of the 'dummy' monomer, 3Ph. Importantly, this seeded supramolecular polymerization process was repeatable as in the case of our previous studies (Fig. S8†)..$^{12,13}$

After the LSP, we obtained a clear solution without any precipitate (Fig. S9†). This was spin-coated on a highly oriented pyrolytic graphite (HOPG). Observation under atomic force microscopy (AFM) revealed the presence of both 1D supramolecular polymers and J-aggregate nanoparticles, consisting of 2Me and 3Ph, respectively (Fig. 6a). Statistical analysis for over 100 objects revealed that the number average length $\left(L_{\mathrm{n}}\right)$ and weight average length $\left(L_{\mathrm{w}}\right)$ of the obtained supramolecular polymers were proportional to the ratio of the concentrations of 2Me in the seed and 2Me in the co-assembled J-aggregate (Fig. 6b and c, and S10 and S11 $\dagger$ ). The polydispersity index (PDI: $L_{\mathrm{w}} / L_{\mathrm{n}}$ ), the distribution of the length, of the thus-obtained supramolecular polymer of $2 \mathrm{Me}$ was 1.36 , which was much smaller than the value predicted based on a thermodynamic equilibrium (2.0). ${ }^{1,12}$ Remarkably, supramolecular polymers obtained in this way did not bundle, which clearly contrasts the structures obtained under thermodynamic control (Fig. 3c). This observation would imply that the strong propensity of precipitation of $2 \mathrm{Me}$ (Fig. 3a-c) originates from heterogeneous secondary nucleation through lateral interactions among the one-dimensional supramolecular polymers. ${ }^{37}$ Thus, LSP allows control over the nucleation-elongation process, leading to 
(a)

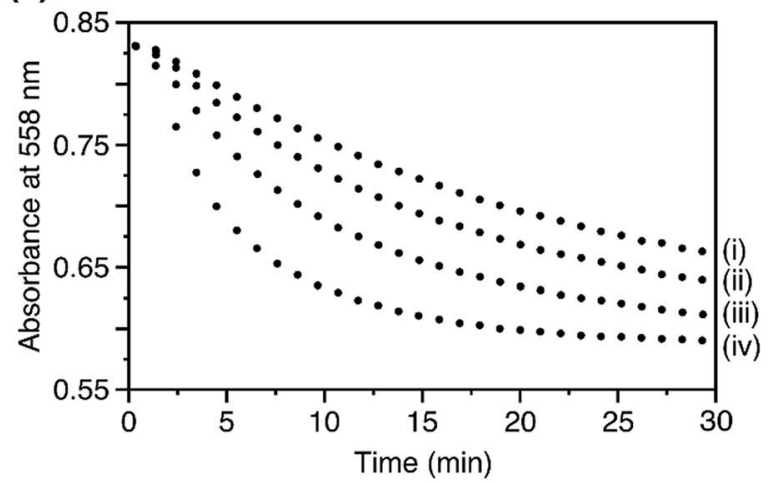

(c)

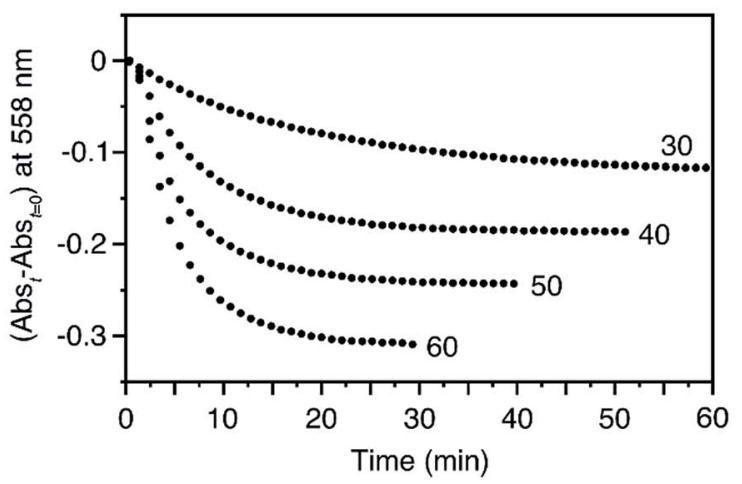

(b)

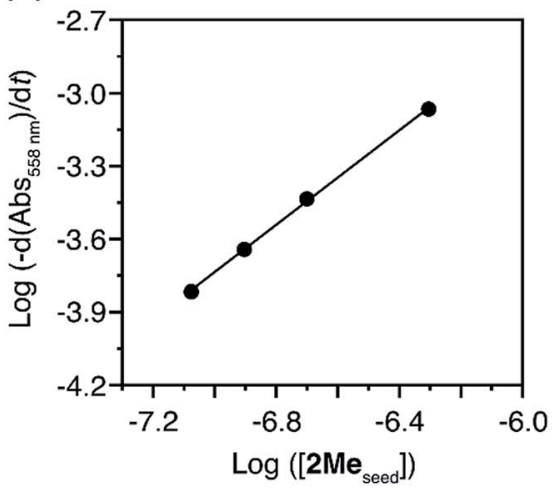

(d)

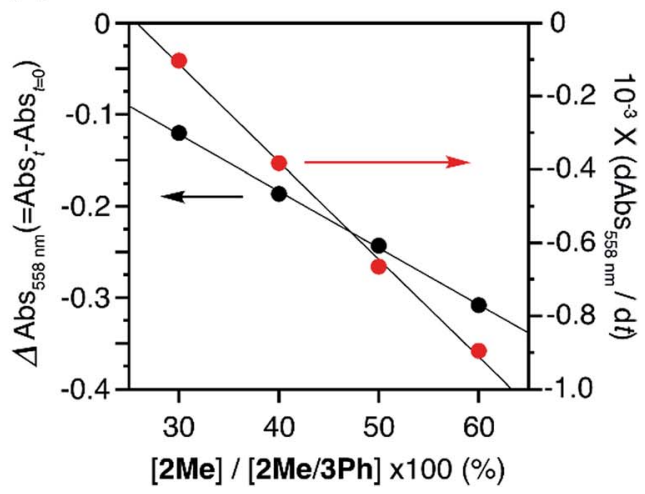

Fig. 5 (a) Plots of the changes in absorbance at $558 \mathrm{~nm}$ upon the addition of $2 \mathrm{Me} \mathrm{H}$-aggregate seeds to the solution of $2 \mathrm{Me} / 3 \mathrm{Ph}$ co-assembled J-aggregates; [ $2 \mathrm{Me}$ in the seed] $=$ (i) 0.084 , (ii) 0.125 , (iii) 0.200 , and (iv) $0.495 \mu \mathrm{M}$, [2Me $+3 \mathrm{Me}$ in the co-assembled J-aggregate] $=50 \mu \mathrm{M}$, molar ratio of $2 \mathrm{Me}: 3 \mathrm{Ph}$ in the co-assembled J-aggregate was $50: 50$. Path length of cuvette $=10 \mathrm{~mm}$. (b) log-log plot of the rate of decrease of absorbance at $558 \mathrm{~nm}$ as a function of the concentration of $2 \mathrm{Me}$ seeds. (c) Plots of the changes in absorbance at $558 \mathrm{~nm}$ upon the addition of $2 \mathrm{Me}$ seeds to the solution of $2 \mathrm{Me} / 3 \mathrm{Ph}$ co-assembled J-aggregates; [ $2 \mathrm{Me}$ in the seed] $=0.495 \mu \mathrm{M}$, [2Me $+3 \mathrm{Me}$ in the co-assembled $\mathrm{J}$ aggregate] $=50 \mu \mathrm{M}$, molar ratios of $2 \mathrm{Me}: 3 \mathrm{Ph}$ in the J-aggregate $=60: 40,50: 50,40: 60$, and $30: 70$. The numerical figures indicate the percentage of $2 \mathrm{Me}$ in the co-assembled J-aggregate. Path length of cuvette $=10 \mathrm{~mm}$. (d) Plots of the net changes in absorbance with time $\left(\mathrm{Abs}_{t=0}-\mathrm{Abs}_{t}: t=30,40,50\right.$, and $60 \mathrm{~min}$ for the ratios (2Me:3Ph) of $60: 40,50: 50,40: 60$, and $30: 70$, respectively) (black circle) and polymerization rates (red circle) as a function of the proportion of $2 \mathrm{Me}$ in the $2 \mathrm{Me} / 3 \mathrm{Ph}$ co-assembled J-aggregates. The polymerization rates were determined by linear analysis for the initial polymerization process (a few minutes after the addition of the seed) in Fig. $5 c$.

(a)

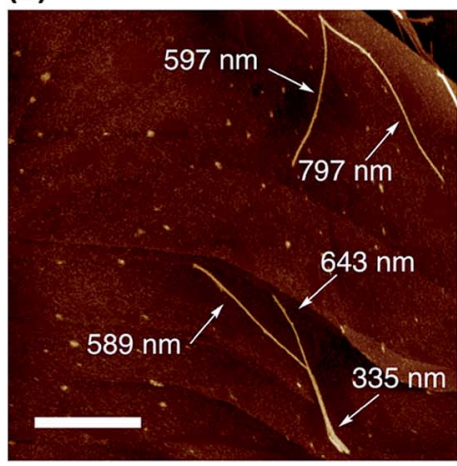

(b)

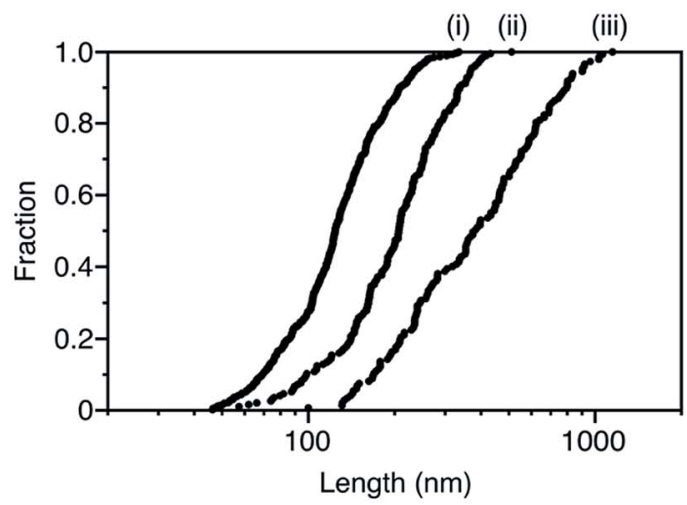

(c)

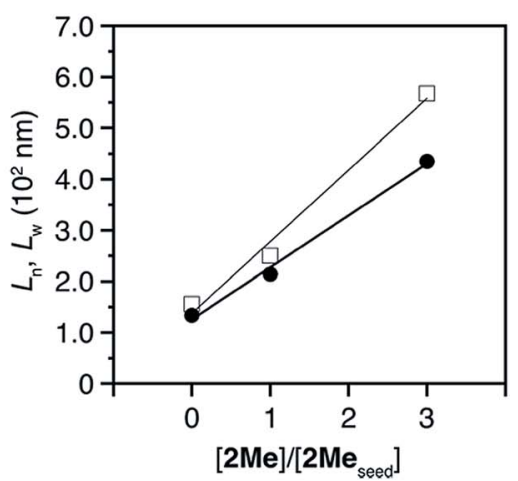

Fig. 6 (a) AFM image (scale bar $=400 \mathrm{~nm}$ ) of the supramolecular polymer of 2Me obtained through LSP using 3Ph as a 'dummy' monomer; [2Me in the seed] : [2Me in the co-assembled J-aggregate] = 1:3; on a HOPG substrate. (b) Histogram of the length distribution of (i) seed and supramolecular polymer of $2 \mathrm{Me}$ obtained under the conditions of [2Me in the seed] : [2Me in the co-assembled J-aggregate] $=$ (ii) $1: 1$ and (iii) $1: 3$. (c) Number average length (filled circle) and weight average length (open square) as a function of the ratio of concentrations of $2 \mathrm{Me}$ in the seed and in the co-assembled J-aggregate. 
control over structures and properties (such as crystallinity) of supramolecular polymers at higher hierarchy.

\section{Conclusions}

In conclusion, we demonstrated a new LSP method for a monomer that spontaneously nucleated without a lag time. We used a 'dummy' monomer that was incapable of 1D supramolecular polymerization but could entrap an active monomer into the dormant state. We note that $2 \mathbf{M e}$ is still a unique monomer in that it undergoes biphasic self-assembly (Fig. 3d). ${ }^{10,11,31}$ Nevertheless, we believe that the present study shows a new possibility of creating a dormant state based on coupled equilibria, which is the key to expanding the scope of LSP and its further applications.

\section{Conflicts of interest}

There are no conflicts to declare.

\section{Acknowledgements}

This work was supported by KAKENHI (JP15H05483 for K. S.), Scientific Research on Innovative Areas "Dynamical ordering of biomolecular systems for creation of integrated functions (JP16H00787 for K. S.)", " $\pi$-System figuration: control of electron and structural dynamism for innovative functions (JP26102009 for M. T.)", and the Nanotechnology Network Project from the Ministry of Education, Culture, Sports, Science and Technology, Japan. T. F. thanks the Japan Society for the Promotion of Science (JSPS) for a research fellowship for young scientists (16J02156) and a postdoctoral fellowship for research abroad.

\section{Notes and references}

1 T. F. A. De Greef, M. M. J. Smulders, M. Wolffs, A. P. H. J. Schenning, R. P. Sijbesma and E. W. Meijer, Chem. Rev., 2009, 109, 5687-5754.

2 M. Ouchi, T. Terashima and M. Sawamoto, Chem. Rev., 2009, 109, 4963-5050.

3 K. Matyjaszewski and J. Xia, Chem. Rev., 2001, 101, 29212990.

4 Z. Chen, A. Lohr, C. R. Saha-Möller and F. Würthner, Chem. Soc. Rev., 2009, 38, 564-584.

5 C. Rest, R. Kandanelli and G. Fernández, Chem. Soc. Rev., 2015, 44, 2543-2572.

6 D. Zhao and J. S. Moore, Org. Biomol. Chem., 2003, 1, 34713491.

7 P. Jonkheijm, P. van der Schoot, A. P. H. J. Schenning and E. W. Meijer, Science, 2006, 313, 80-83.

8 M. M. J. Smulders, M. M. L. Nieuwenhuizen, T. F. A. De Greef, P. Schoot, A. P. H. J. Schenning and E. W. Meijer, Chem.-Eur. J., 2010, 16, 362-367.

9 P. A. Korevaar, S. J. George, A. J. Markvoort, M. M. J. Smulders, P. A. J. Hilbers, A. P. H. J. Schenning,
T. F. A. De Greef and E. W. Meijer, Nature, 2012, 481, 492496.

10 F. Fennel, S. Wolter, Z. Xie, P.-A. Plöz, O. Kürn, F. Würthner and S. Lochbrunner, J. Am. Chem. Soc., 2013, 135, 1872218725.

11 M. F. J. Mabesoone, A. J. Markvoort, M. Banno, T. Yamaguchi, F. Helmich, Y. Naito, E. Yashima, A. R. A. Palmans and E. W. Meijer, J. Am. Chem. Soc., 2018, 140, 7810-7819.

12 S. Ogi, K. Sugiyasu, S. Manna, S. Samitsu and M. Takeuchi, Nat. Chem., 2014, 6, 188-195.

13 T. Fukui, S. Kawai, S. Fujinuma, Y. Matsushita, T. Yasuda, T. Sakurai, S. Seki, M. Takeuchi and K. Sugiyasu, Nat. Chem., 2017, 9, 493-499.

14 T. Fukui, T. Uchihashi, N. Sasaki, H. Watanabe, M. Takeuchi and K. Sugiyasu, Angew. Chem., Int. Ed., 2018, 57, 1546515470.

15 A. T. Haedler, S. C. J. Meskers, R. H. Zha, M. Kivala, H.-W. Schmidt and E. W. Meijer, J. Am. Chem. Soc., 2016, 138, 10539-10545.

16 X. Ma, Y. Zhang, Y. Zhang, Y. Liu, Y. Che and J. Zhao, Angew. Chem., Int. Ed., 2016, 55, 9539-9543.

17 G. Ghosh and S. Ghosh, Chem. Commun., 2018, 54, 57205723.

18 J. Kang, D. Miyajima, T. Mori, Y. Inoue, Y. Itoh and T. Aida, Science, 2015, 347, 646-651.

19 S. Ogi, V. Stepanenko, K. Sugiyasu, M. Takeuchi and F. Würthner, J. Am. Chem. Soc., 2015, 137, 3300-3307.

20 S. Ogi, V. Stepanenko, J. Thein and F. Würthner, J. Am. Chem. Soc., 2016, 138, 670-678.

21 W. Wagner, M. Wehner, V. Stepanenko, S. Ogi and F. Würthner, Angew. Chem., Int. Ed., 2017, 56, 16008-16012.

22 S. Ogi, K. Matsumoto and S. Yamaguchi, Angew. Chem., Int. Ed., 2018, 57, 2339-2343.

23 E. E. Greciano, B. Matarranz and L. Sanchez, Angew. Chem., Int. Ed., 2018, 57, 4697-4701.

24 M. Endo, T. Fukui, S. H. Jung, S. Yagai, M. Takeuchi and K. Sugiyasu, J. Am. Chem. Soc., 2016, 138, 14347-14353.

25 A. Pal, M. Malakoutikhah, G. Leonetti, M. Tezcan, M. Colomb-Delsuc, V. D. Nguyen, J. van der Gucht and S. Otto, Angew. Chem., Int. Ed., 2015, 54, 7852-7856.

26 E. M. Robinson, D. J. Lunn, A. Nazemi, G. R. Whittell, L. De Cola and I. Manners, Chem. Commun., 2015, 51, 1592115924.

27 M. E. Robinson, A. Nazemi, D. J. Lunn, D. W. Hayward, C. E. Boott, M.-S. Hsiao, R. L. Harniman, S. A. Davis, G. R. Whittell, R. M. Richardson, L. De Cola and I. Manners, ACS Nano, 2017, 11, 9162-9175.

28 S. H. Jung, D. Bochicchio, G. M. Pavan, M. Takeuchi and K. Sugiyasu, J. Am. Chem. Soc., 2018, 140, 10570-10577.

29 A. Mishra, D. B. Korlepara, M. Kumar, A. Jain, N. Jonnalagadda, K. K. K. Bejagam, S. Balasubramanian and S. J. George, Nat. Commun., 2018, 9, 1295.

30 A. Jain, S. Dhiman, A. Dhayani, P. K. Vemula and S. J. George, Nat. Commun., 2019, 10, 450.

31 S. Ogi, T. Fukui, M. L. Jue, M. Takeuchi and K. Sugiyasu, Angew. Chem., Int. Ed., 2014, 53, 14363-14367. 
32 T. Shimizu and M. Masuda, J. Am. Chem. Soc., 1997, 119, 2812-2818.

33 N. Fujita, Y. Sakamoto, M. Shirakawa, M. Ojima, A. Fujii, M. Ozaki and S. Shinkai, J. Am. Chem. Soc., 2007, 129, 4134-4135.

34 M. M. Safont-Sempere, G. Fernández and F. Würthner, Chem. Rev., 2011, 111, 5784-5814.
35 T. Fukui, M. Takeuchi and K. Sugiyasu, Sci. Rep., 2017, 7, 2425.

36 K. Aratsu, D. D. Prabhu, H. Iwawaki, X. Lin, M. Yamauchi, T. Karatsu and S. Yagai, Chem. Commun., 2016, 52, 82118214.

37 J. Chen, E. Zhu, J. Liu, S. Zhang, Z. Lin, X. Duan, H. Heinz, Y. Huang and J. J. De Yoreo, Science, 2018, 362, 1135-1139. 